\title{
THE CHARACTERISTICS OF BIKE-SHARING USAGE: CASE STUDY IN ZHONGSHAN, CHINA
}

\author{
Y. ZHANG ${ }^{1}$, T. THOMAS ${ }^{2}$, M.J.G. BRUSSEL ${ }^{1}$ \& M.F.A.M. VAN MAARSEVEEN ${ }^{1}$ \\ ${ }^{1}$ Faculty of Geo-Information Science and Earth Observation (ITC), University of Twente, the Netherlands. \\ ${ }^{2}$ Centre for Transport studies, University of Twente, the Netherlands.
}

\begin{abstract}
Public bike systems have grown in popularity and are expanding rapidly across cities worldwide. Such systems provide access to pickup and drop-off public bikes at numerous bike stations for free or for an affordable fee and aim at increasing bike use and extending the accessibility of traditional public transport systems. A variety of studies have examined the characteristics of bike-sharing systems, mostly in American and European cities and with a focus on user demographics. The objective of this study is to investigate the general characteristics of system usage, in terms of system efficiency, trip characteristics and bike activity patterns, for Zhongshan's public bike system during a five-month period. The findings show that the system is not very efficient based on usage metrics which are low compared to successful systems in other countries. Demand is relatively high in city centre zones due to high population and activity density. However, there is no clear direction of inbound or outbound trips in rush hours. This may be attributed not only to mixed land use patterns throughout the city, but also to the fact that most trips are local trips over short distance. This could indicate that public bike trips are mainly substitute for walking trips rather than for car or PT trips. On the outskirts, demand and system efficiency are low, indicating that location allocation of stations needs adjustment. In the conclusions, we discuss how these findings can be used for improving the system.

Keywords: bike-sharing, bike activity patterns, system efficiency, trip characteristics.
\end{abstract}

\section{INTRODUCTION}

Emerging as an innovative and green mode of public transport, public bike systems provide public access to rent and return bikes at numerous bike stations across an urban area. Such systems not only act as a unimodal system, but also contribute to bridging the gap in urban transport systems to solve the 'last mile' problem [1]. Growing concerns about fast motorization and urban pollution have led to increasing interests in bikesharing programmes across the world, from Europe to America, Asia and Australia [2]. As a result of technological advances and innovations, modern bike-sharing programmes enable users to monitor the number of available bikes and parking slots via real-time online maps or mobile apps, and generate station-based or trip-level usage data [3]. Currently, approximately 600 bike-sharing systems are in operation, and many systems are planned for the near future [4].

Some early studies have conducted surveys to analyse the operation and usage of bikesharing systems. In cities with successful bike-sharing systems these studies reported reduced car use and an increase in cycling [2]. Some surveys revealed that car owners and individuals, who like bike-sharing programmes, tended to use public bikes more often [5, 6]. The proximity of home locations to bike stations and the ownership of bike-sharing

\footnotetext{
WIT 变

This paper is part of the proceedings of the 22nd International Conference on Urban Transport and the Environment (Urban Transport 2016)

www.witconferences.com
} 
membership have a positive effect on shared bicycle use [5]. The shared bicycles have acted as a competitor to bus transit, walking, autos and taxis [7].

The availability of operational usage data, e.g. station-based data or trip-level data, enabled new research possibilities in recent years. Few studies employed data mining techniques to explore the temporal patterns of bike use, based on station data. Froehlich et al. [8] clustered stations of Barcelona's public bike system based on bicycle activity, and Kaltenbrunner et al. [9] extended the former analysis by predicting bicycle activity at Barcelona's stations over the hours of the day. Vogel et al. [10] explored activity patterns at stations of Vienna's system. Borgnat et al. [11] examined temporal patterns of bike use on system scale in Lyon and predicted levels of bike use on a daily and hourly basis. They found that weekday and weekend usage peaks are quite different and that at station level the differences in peak usage might be associated with the kind of activities in the direct neighbourhood.

Some studies looked at specific features of a bike-sharing system in a city. By analysing 11.6 million bike-sharing trips, Jensen et al. [12] found that public bikes compete with cars in terms of speed in downtown Lyon. Based on station data, Jäppinen et al. [13] indicated that integration of public bikes with traditional public transportation can promote sustainable daily mobility in Helsinki. Zhao et al. [14] highlighted that on weekdays, women tend to make multiple-circle trips and spend more time in cycling than men do, based on the trip data from Nangjing, China. Several studies explored London's public bike system. These studies found that two strikes of the London subway increased the number and duration of public bike trips [15] and concluded that easier access to the system can promote weekday commuting and weekend use [16].

Recently, some studies analysed a larger set of bike-sharing systems. O'Brien et al. [3] proposed several metrics to measure system characteristics and gave a classification of 38 public bike systems worldwide, based on system metrics - such as system size, daily usage, bike occupancy of each station, spatial compactness of bike stations and average number of available bikes over the time of day. They demonstrated that Asian systems have lower compactness than European/Middle Eastern systems and that Chinese systems group together based on system metrics. Zhao et al. [17] analysed the effects of urban population, government expenditure, system size and operation policy on daily bike use by comparing 69 Chinese bike-sharing systems. They recommended a bike-member ratio of less than 0.2 and the adoption of personal credit and universal cards to access to systems. An ITDP report by Gauthier et al. [18] developed a guideline for bike-sharing planning based on experiences of best used and most efficient systems worldwide. They discussed and proposed a series of factors related to system performance; for example, the system is considered to be efficient if on average each bike is used four to eight times daily, and the ratio of parking docks to bike is $2-2.5$.

However, few scientific studies that have been reported analyse the factual use of a bikesharing system employing the information embedded in the operational database. This information might be beneficial for further improvement and expansion of existing systems as well as the adoption of new systems.

In this study, we focus on system efficiency, trip characteristics and bike activity patterns. To analyse the spatial dimension we introduced six zones demarcated by concentric circles based on the distance to the city centre (Fig. 2). The study was conducted for the bike-sharing system in Zhongshan, China, using trip data during the five-month period from February 2014 to June 2014. 
The article is organized as follows. Section 2 briefly describes the study context, the bikesharing system in Zhongshan and the available database. Section 3 contains the main results of the analysis with respect to system efficiency, trip characteristics and bike activity patterns at station level. Finally, Section 4 presents the main conclusions of the study.

\section{RESEARCH CONTEXT}

\subsection{Study context}

In China, bicycle evolution has gone through four phases from initial entry and slow growth (1900s-1978), to rapid growth (1978-1995), bicycle use decrease (1995-2002) and policy diversification (2002-present) [19]. This transition is associated with rapid motorization and a gradually deteriorating cycling environment, as a result of economic growth, fast urbanization and a negative attitude of governmental transport policies towards cycling [19]. To alleviate serious traffic congestion and air pollution, China's planners and decision-makers have gradually shifted their focus from offering additional road space for motorized vehicles to examining the need for sustainable transportation strategies [17]. Two innovative bicycle forms emerged: electric bikes and public bike systems [19]. Along with adopting and advocating the policy on 'Transit Priority' that emphasizes the development and improvement of public transport systems, public bike programmes have been set up that expanded rapidly although the history of such systems is still short in China. At present, more than 160 public bike systems are running in China, and more and more systems will be in operation in the near future.

\subsection{Study area and data preparation}

Zhongshan city is a prefecture-level city that is located in the Guangdong province of China, directly opposite to Hong Kong. The city government administers six districts covering the urban area, and 18 towns (Fig. 1(A)). Zhongshan's bike-sharing system was launched in 2011 and is a 24/7 self-service system. After registration, users can pick up and return public bikes at any station during the day, using a smart membership card. For each trip, the first hour is free, and any extra hours are charged at an incremental price (1 CNY per hour), which is much cheaper than a trip by local public bus (2 CNY per trip). The system gradually expanded from the central area to the distant industrial district, and further expansion over the city is ongoing.

Trip data from February 2014 to June 2014 were provided by the Transport Department of the Urban Planning and Design Institute of Zhongshan. In June 2014, according to the trip database, 296 bike stations equipped with 7,855 parking docks were distributed over the urban area, implying an average station size of 26.5 docks. As shown in Fig. 1(B), 224 of these stations were built before 2014, mainly located in the 'major urban area', and in 2014, 72 bike stations were built, predominantly located in 'Torch Hi-tech Industrial Development district'. The average distance between neighbouring stations is $377 \mathrm{~m}$.

In the trip database each trip record includes user ID, bike ID, pickup and return station, and start and end time of the trip. During the five-month period the original trip database contained 1,937,265 records (i.e. trips). In the data-cleaning process, $6 \%$ of the records had to be excluded for trips that lasted less than 1 min, mostly starting and ending at the same station. As a result, 1,820,954 valid records were obtained. 


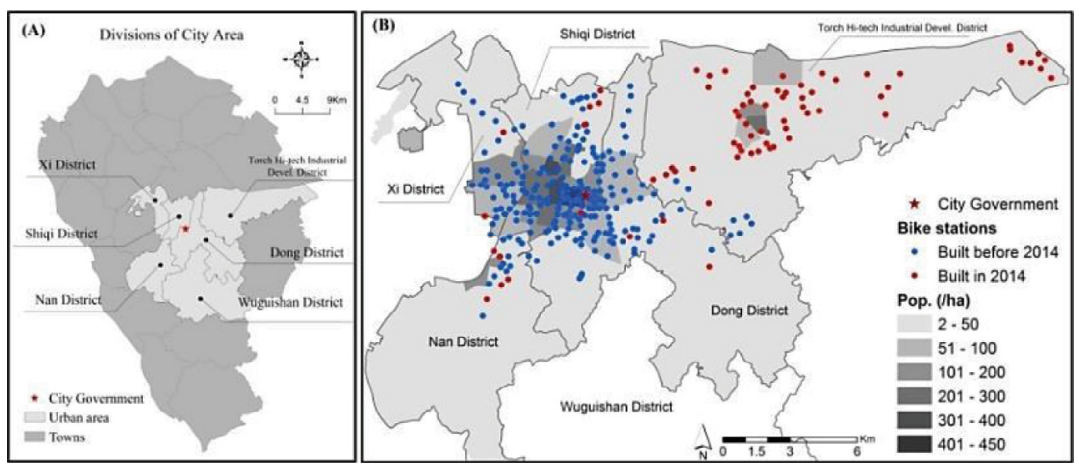

Figure 1: (A) Map of city area, (B) spatial distribution of bike stations and population density in the urban area.

\subsection{Characteristics in bicycle use: the user perspective}

Employing the (anonymous) 'User-ID', users have been classified into five groups - User1, User2, User3, User4 and User5 - based on the number of months within the observation period the person used the system. For example, User3 represents persons that used the system in three out of the five months. User1 and User5 account for $27 \%$ and $23 \%$ of the total user population, respectively, which is larger than the other user groups. The majority of the User1 group only used the system on weekdays, whereas the majority of all other user groups used the system both on weekdays and in the weekend. The User1 group contains many incidental users, who used the system just once. The more months people are using the system correlates with a higher frequency in number of days per week as well as per month.

This finding suggests two types of users: (1) incidental users, e.g. the User1 group; and (2) regular users, e.g. User3, User4 and User5 groups. Users have to register as a member before they can use the system. This registration procedure might reduce the attractiveness of the system for incidental users. In order to encourage more people to participate in such a system, it would be worthwhile to investigate the possibilities to simplify the access procedure. Lathia et al. [16] showed that introduction of an easier access procedure has raised bike use of London's public bike system.

\section{CHARACTERISTICS OF SYSTEM USAGE}

A quantitative analysis has been conducted to investigate the characteristics of system usage, in terms of system efficiency, trip characteristics and bike activity patterns. The analysis looked at the system as a whole as well as at parts of the system spatially to uncover the performance of the system across the urban area. For the spatial analysis, the urban area has been divided into six zones using five concentric rings around the city centre as shown in Fig. 2. The six zones cover all bike stations and the vast majority of the urban area. The first ring is the central zone with the highest population density, whereas each successive ring has a lower population density. Zone 6 covers the hi-tech industrial district and contains the stations newly built in 2014 . 


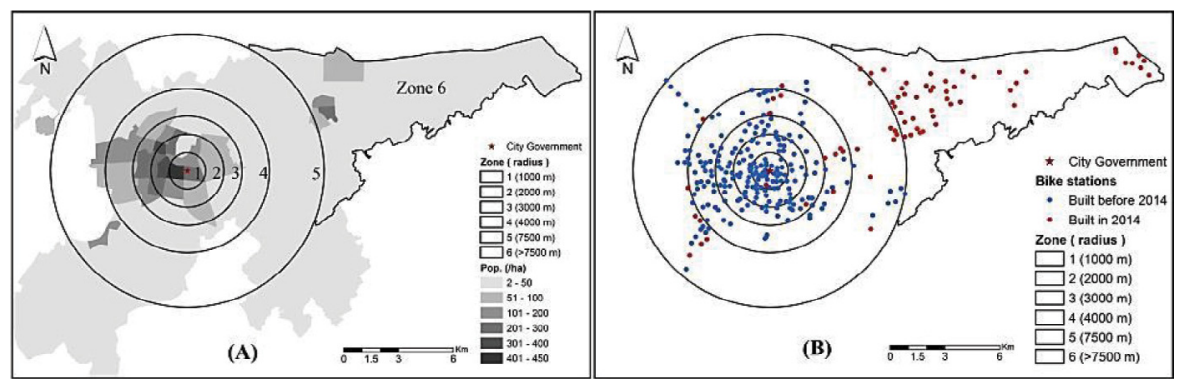

Figure 2: Six spatial zones with (A) population density and (B) bike stations in the urban area.

\subsection{System efficiency}

Table 1 presents the system metrics at system level as well as for each spatial zone. The total number of bikes is 4,072 yielding a slot/bike ratio of 1.9 and on average 5.4 bikes/1,000 inhabitants. These values are lower than the ideal values of $2-2.5$ and $10-30$, respectively, as proposed by Gauthier et al. [18]. It implies that from an efficiency perspective there might be insufficient slots and bikes. Knowing that station density has a positive effect on bike use [18], the station density of 11 stations $/ \mathrm{km}^{2}$ in the central zone 1 fits within the bandwidth of 10-16 stations $/ \mathrm{km}^{2}$, as suggested by Gauthier et al. [18]. However, all other zones have a substantial lower station density, resulting in a low station density at system level. For simplicity, to get an indication for the number of bikes per 1,000 inhabitants for each zone, we assumed a constant slot/bike ratio over the whole area.

At system level the average daily number of bikes in use is 2,543 on weekdays and 2,394 on weekends, indicating that only approximately $60 \%$ of all bikes are used every single day. According to the number of daily trips/station in Table 2, the demand is relatively high in the central zone 1 and decreases in successive zones. Since the number of stations in the latter zones is higher than in zone 1, this finding suggests that both bikes and stations are used ineffectively, especially in the zones that are further from the city centre.

Table 1: System metrics.

\begin{tabular}{lccccccc}
\hline & $\begin{array}{c}\text { Whole } \\
\text { system }\end{array}$ & Zone 1 & Zone 2 & Zone 3 & Zone 4 & Zone 5 & Zone 6 \\
& 296 & 33 & 54 & 54 & 63 & 47 & 45 \\
Stations & 4,072 & 424 & 742 & 765 & 870 & 660 & 611 \\
Bikes & 1.9 & 1.9 & 1.9 & 1.9 & 1.9 & 1.9 & 1.9 \\
Slots/bike & 1.24 & 11 & 6 & 3.6 & 1.8 & 0.42 & 0.71 \\
Station density $\left(/ \mathrm{km}^{2}\right)$ & 27 & 25 & 27 & 27 & 27 & 27 & 26 \\
Slots/station & 5.4 & 6.3 & 6.7 & 6.4 & 7.8 & 3.5 & 3.8 \\
Bike/1,000 inhabitants & & & & & & &
\end{tabular}


Table 2 : Daily use of the system on weekdays.

\begin{tabular}{lccccccc}
\hline & $\begin{array}{c}\text { Whole } \\
\text { system }\end{array}$ & Zone 1 & Zone 2 & Zone 3 & Zone 4 & Zone 5 & Zone 6 \\
& 12,871 & 4,579 & 6,823 & 4,734 & 2,454 & 902 & 169 \\
\hline Daily trips & 43 & 139 & 126 & 88 & 39 & 19 & 4 \\
Daily trips/station & 1.64 & 5.60 & 4.77 & 3.21 & 1.46 & 0.71 & 0.14 \\
Daily trips/slot & 3.2 & 10.8 & 9.2 & 6.2 & 2.8 & 1.4 & 0.3 \\
Daily trips/bike & 17 & 68 & 62 & 40 & 22 & 5 & 1 \\
$\begin{array}{l}\text { Daily trips/1,000 } \\
\text { inhabitants }\end{array}$ & & & & & & & \\
\hline
\end{tabular}

Gauthier et al. [18] also proposed values for the performance metrics daily trips per bike (i.e. 4-8) and daily trips per 1,000 inhabitants (i.e. 25-50). The former metric indicates efficiency of bike use and the latter market penetration. For zone 1, 2 and 3 the average daily trips/bike is 10.8, 9.2 and 6.2, respectively; and the average daily trips/1,000 inhabitants is 68, 62 and 40, respectively. Therefore, the three most central zones have both a high efficiency of bike use and a high market penetration comparable to Paris and Barcelona [18]. However, for the peripheral zones 4,5 and 6 both values are very low, contributing substantially to the low performance values for the overall system, that is, 3.2 daily trips per bike and 17 daily trips per 1,000 inhabitants. The low demand in peripheral zones might be attributed to the low station density. It is recommended to investigate whether in these zones an increase in station density potentially combined with a capacity reduction in slots per station might have a positive impact on demand.

\subsection{Trip characteristics}

In terms of trip characteristics, we focused on two aspects: (1) the origin-destination (OD) pattern of trips and (2) trip duration. The OD matrix of public bike trips in Table 3 indicates that there is no strong orientation of trips towards or from the city centre. The majority of trips are intra-zonal or between adjacent zones. The further away from the city centre, the larger the proportion of intra-zonal trips. In particular in zone 6, intra-zonal trips account for $86.1 \%$ of the trip generation, posing almost an image of a stand-alone system.

Figure 3 shows the distribution of trip durations. Trip duration is defined as the difference between return time and pickup time of the bike. Distributions are provided for weekdays and weekends (Fig. 3(A)), as well as peak and off-peak hours (Fig. 3(B)), and average trip times are given for origins and destinations (Fig. 3(C)). The distributions are quite similar in all three figures: the average trip duration is less than $16 \mathrm{~min}$, most trips last less than $30 \mathrm{~min}$ and the vast majority of trips finish within one hour (the free of charge period).

According to Fig. 3(A) and (B), there is no significant difference in trip durations between weekdays and weekends and between peak and off-peak hours. However, the average duration of $\mathrm{O}-\mathrm{O}$ trips - i.e. trips that start and end at the same station - is 2.5 times longer than the duration of $\mathrm{O}-\mathrm{D}$ trips (i.e. trips that end at a different station than the pickup station), as shown in Fig. 3(C). The presumable explanation is that these trips refer to round trips for which some activity time is included in the trip duration, and the user is not willing or able to dock the bike near the activity location. 
Table 3: O-D matrix of public bike trips (weekdays).

\begin{tabular}{lrrrrrrr}
\hline & $\begin{array}{c}\text { Zone 1 } \\
(\%)\end{array}$ & \multicolumn{1}{c}{$\begin{array}{c}\text { Zone 2 } \\
(\%)\end{array}$} & $\begin{array}{c}\text { Zone 3 } \\
(\%)\end{array}$ & $\begin{array}{c}\text { Zone 4 } \\
(\%)\end{array}$ & $\begin{array}{c}\text { Zone 5 } \\
(\%)\end{array}$ & $\begin{array}{c}\text { Zone 6 } \\
(\%)\end{array}$ & $\begin{array}{c}\text { Total } \\
(\%)\end{array}$ \\
\hline Zone 1 & 49.89 & 38.59 & 9.45 & 1.76 & 0.31 & 0.01 & 100 \\
Zone 2 & 25.74 & 46.19 & 23.12 & 4.40 & 0.53 & 0.01 & 100 \\
Zone 3 & 9.39 & 32.77 & 42.04 & 14.28 & 1.50 & 0.03 & 100 \\
Zone 4 & 3.01 & 11.62 & 26.31 & 47.87 & 11.10 & 0.08 & 100 \\
Zone 5 & 1.41 & 2.87 & 6.41 & 30.80 & 55.60 & 2.91 & 100 \\
Zone 6 & 0.17 & 0.56 & 0.56 & 0.67 & 11.93 & 86.10 & 100 \\
\hline
\end{tabular}
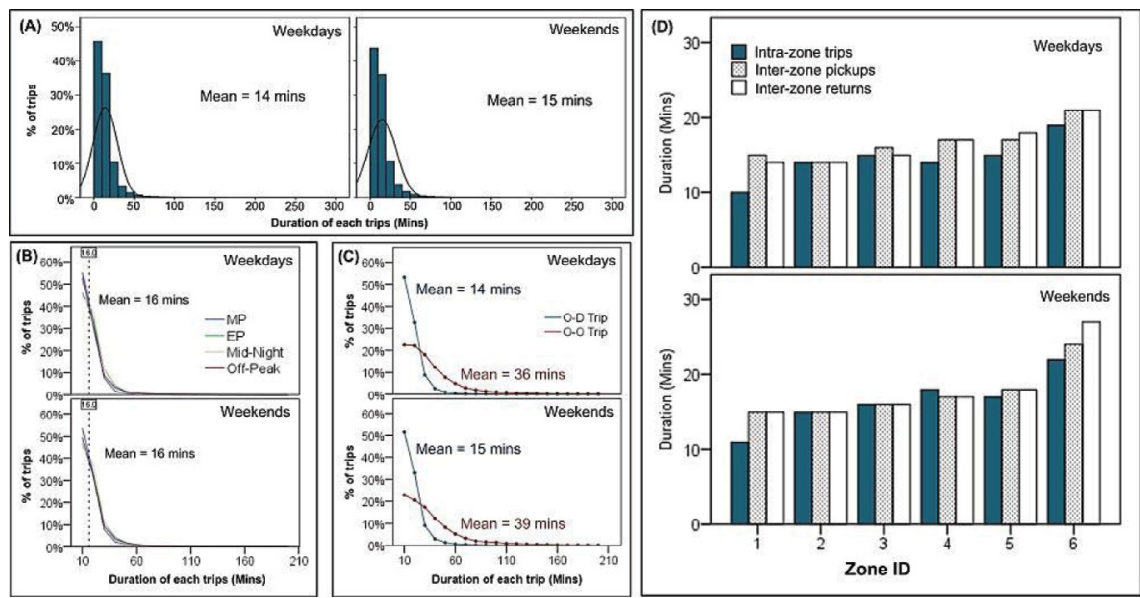

Figure 3: Distribution functions and averages of trip durations.

Figure 3(D) shows the average trip duration for intra-zonal trips, inter-zonal pickups and inter-zonal returns for each of the zones. Except for zone 1, average trip duration for inter-zonal trips is equal to the one for intra-zonal trips, suggesting that origin and destination stations for inter-zonal trips are not far from each other. For zone 1 the lower intra-zonal average trip duration is probably due to the high station density in this zone. Figure 3(D) also shows gradually increasing average trip duration for both intra-zonal and inter-zonal trips, with the further the distance from a zone to the city centre. The most likely explanation is the gradually decreasing station density.

\subsection{Bicycle activity patterns at station level}

The analysis on bicycle activity at station level provides insight in both pickups and return activities over the hours of the day. This information could be very valuable in identifying hotspots and for redistribution of public bikes and planning of the future expansion of the system [9]. In this study, we performed a hierarchical cluster analysis [20] to group 296 stations based on the temporal patterns of average pickups and returns over the hours of the day. Weekdays have been analysed separately from weekends. 


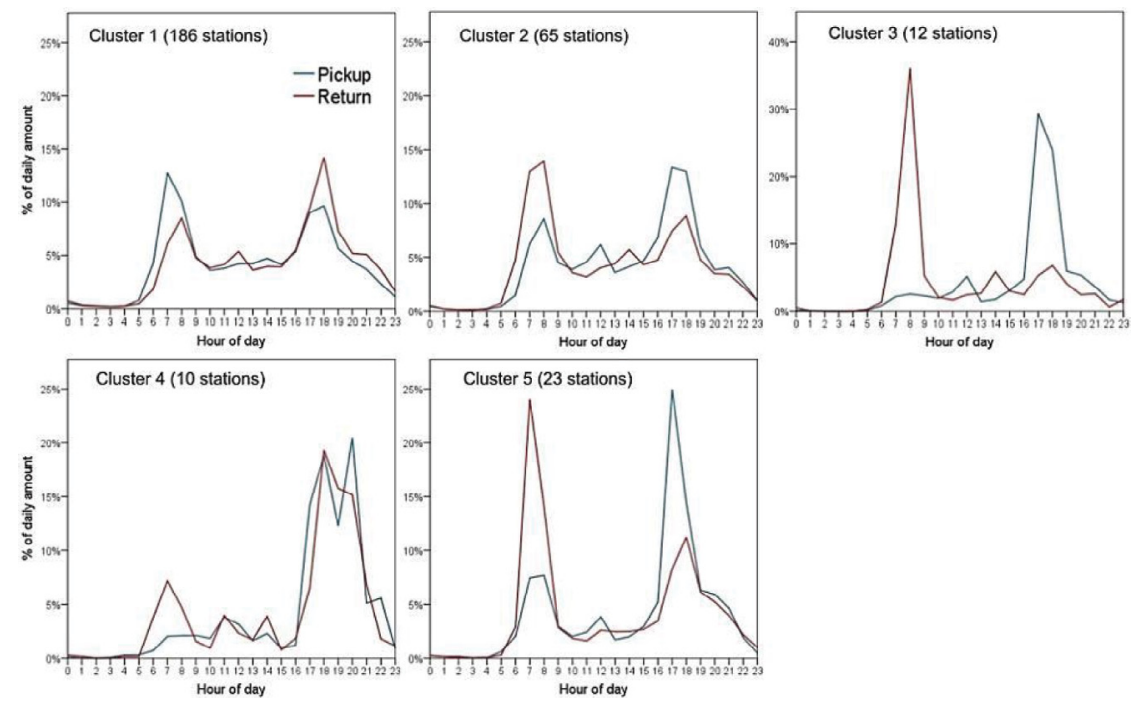

Figure 4: Weekday patterns of bicycle activity at stations.

Figure 4 shows the resulting five clusters of bike activity patterns at stations on weekdays. Clearly visible are a morning peak between 7 and 9 AM, an evening peak between 5 and 7 $\mathrm{PM}$, as well as a small lunch peak between $12 \mathrm{AM}$ and $2 \mathrm{PM}$, when some people go home for lunch and rest, a conventional lifestyle in China in medium- and small-sized cities.

Cluster 1, accounting for $63 \%$ of all stations, shows a moderate pattern of morning pickups and evening returns with a higher pickup activity in the morning peak and a higher return activity in the evening peak. The differences in peak activity are in both cases some $5 \%$ of the daily total.

Cluster 2 with $22 \%$ of all stations features an opposite pattern to cluster 1 . These stations show a higher return activity in the morning peak, and the other way around in the evening peak. Again the differences in peak activity are some 5\% of the daily total in both cases.

Both cluster 3 and cluster 5 show a dominant return activity in the morning peak and a dominant pickup activity in the evening peak. The differences in peak activity are the highest among all clusters and substantial: some $35 \%$ for cluster 3 and $20 \%$ for cluster 5 .

Cluster 4 with the smallest number of stations appears to be a special case. It shows a moderate dominant return activity in the morning peak, whereas both pickup and return activities in the evening peak are high. There are two peaks of pickup activity in the evening, and both account for $20 \%$ of daily pickups from the station.

Figure 5 shows the spatial distribution of these station clusters. The larger clusters 1 and 2 are spread over all zones, except zone 6 . These stations are located in areas with mixed land use patterns, and the predominant land use type determines to which of the two activity patterns the station is clustered. The central zones 1 and 2 are primarily occupied with stations of cluster 1 and cluster 2. Clusters 3 and 5 can be found mainly in the peripheral zones 4,5 and 6. These stations are located in the neighbourhood of shopping malls, offices and colleges/schools, for which the majority of users arrive for work in the morning peak and leave for home in the evening peak. The small and peculiar cluster 4 relates to zone 6 , the hi-tech industrial district, where land use differs substantially from the other areas.

In addition, weekend patterns were classified into four clusters, which are comparable with the first four clusters for weekday patterns. Although morning and evening peaks are also 


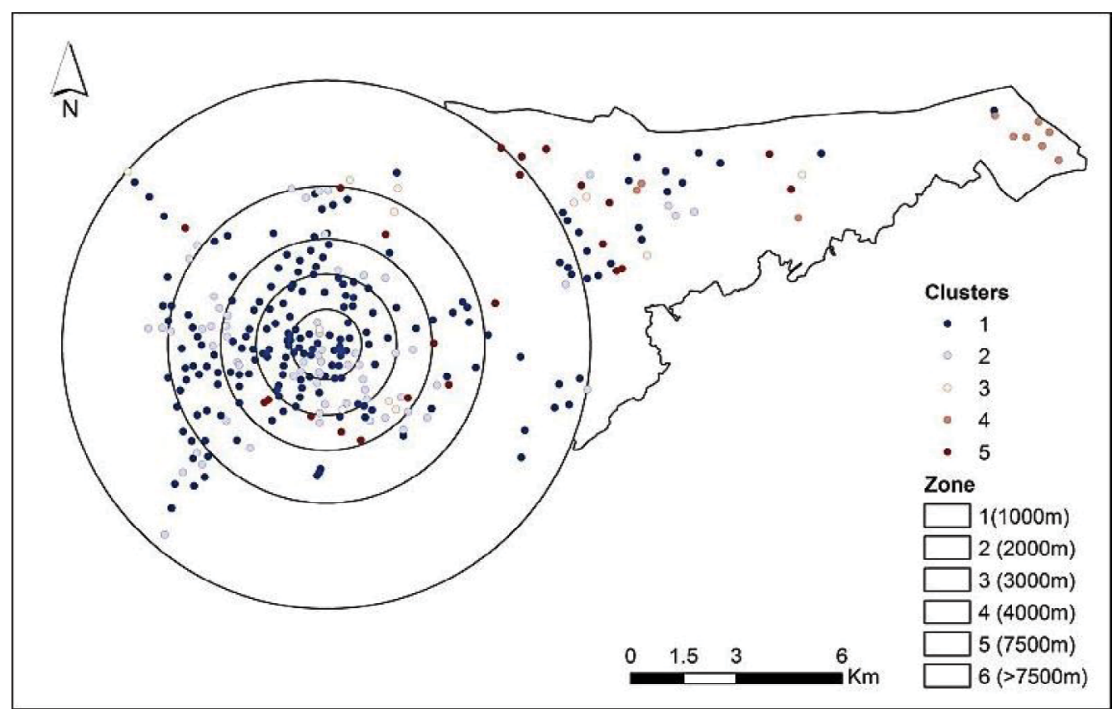

Figure 5: Spatial distribution of station clusters.

visible in weekends, the share of daily trips in peak hours in weekends is some $5 \%$ less than on weekdays. In contrast to Western cities that show commuting on weekdays and leisure trips in weekends, many people in Chinese cities commute both on weekdays and in weekends $[3,14]$.

\section{CONCLUSIONS}

This article investigates characteristics of system usage, in terms of system efficiency, trip characteristics and bike activity patterns, using operational trip data for a five-month period of Zhongshan's public bike system. These characteristics were analysed on system level as well as at a disaggregated level of six concentric zones.

The overall system is not very efficient in comparison with metrics derived from a global analysis by Gauthier et al. [18]. This finding is mainly attributed to the low bike use and low market penetration in peripheral zones. To improve system efficiency, an increase in station density in these areas, possibly combined with a reduction in station capacity, would be worthwhile to consider.

Public bike demand is relatively high in central zones, where population density is the highest and urban activities are concentrated. However, there is no specific orientation of trips to or from the city centre. The majority of public bike trips are short-distance trips within or between adjacent zones. This finding suggests that public bike trips mainly substitute for walking trips rather than for car or public transport trips. Moreover, there is no clear direction of inbound or outbound trips in rush hour. In contrast to Western cities, weekdays and weekends show similar patterns, for many people in China commute both on weekdays and in weekends $[3,14]$.

Finally, two types of users need to be distinguished based on the frequency of bike use: 'incidental users' and 'regular users'. From a policy perspective, simplifying the access procedure for 'incidental users' might encourage more people to use the system and to improve the turnover of bike use. Lathia et al. [16] have shown that the introduction of an easier access procedure has raised bike use of London's public bike system. 


\section{REFERENCES}

[1] Liu, Z., Jia, X. \& Cheng, W., Solving the last mile problem: ensure the success of public bicycle system in Beijing. Procedia - Social and Behavioral Sciences, 43, pp. 73-78, 2012. DOI: 10.1016/j.sbspro.2012.04.079.

[2] Shaheen, S., Guzman, S. \& Zhang, H., Bikesharing in Europe, the Americas, and Asia Past, Present, and Future. Transportation Research Record, 2143, pp. 159-167, 2010. DOI: $10.3141 / 2143-20$.

[3] O’Brien, O., Cheshire, J. \& Batty, M., Mining bicycle sharing data for generating insights into sustainable transport systems. Journal of Transport Geography, 34, pp. 262 273, 2014. DOI: 10.1016/j.jtrangeo.2013.06.007.

[4] ITDP-China, http://www.publicbike.net/defaulten.aspx

[5] Shaheen, S., Zhang, H., Martin, E. \& Guzman, S., Hangzhou public bicycle: understanding early adoption and behavioral response to bikesharing in Hangzhou, China. Transportation Research Record, 2247, pp. 34-41, 2011. DOI: 10.3141/2247-05.

[6] Bachand-Marleau, J., Lee, B. \& El-Geneidy, A., Better understanding of factors influencing likelihood of using shared bicycle systems and frequency of use. Transportation Research Record, 2314, pp. 66-71, 2012. DOI: 10.3141/2314-09.

[7] Parkes, S.D., Marsden, G., Shaheen, S.A. \& Cohen, A.P., Understanding the diffusion of public bikesharing systems: evidence from Europe and North America. Journal of Transport Geography, 31, pp. 94-103, 2013. DOI: 10.1016/j.jtrangeo.2013.06.003.

[8] Froehlich, J., Neumann, J. \& Oliver, N., Sensing and predicting the pulse of the city through shared bicycling. Proceedings of 21 st International Joint Conference on Artificial intelligence, eds. Pasadena, California, USA, pp. 1420-1426, 2009.

[9] Kaltenbrunner, A., Meza, R., Grivolla, J., Codina, J. \& Banchs, R., Urban cycles and mobility patterns: Exploring and predicting trends in a bicycle-based public transport system. Pervasive and Mobile Computing, 6, pp. 455-466, 2010. DOI: 10.1016/j. pmcj.2010.07.002.

[10] Vogel, P., Greiser, T. \& Mattfeld, D.C., Understanding bike-sharing systems using data mining: Exploring activity patterns. Procedia - Social and Behavioral Sciences, 20, pp. 514-523, 2011. DOI: 10.1016/j.sbspro.2011.08.058.

[11] Borgnat, P., Abry, P., Flandrin, P., Robardet, C., Rouquier, J.B. \& Fleury, E., Shared bicycles in a city: a signal processing and data analysis perspective. Advances in Complex Systems, 14, pp. 415-438, 2011. DOI: 10.1142/S0219525911002950.

[12] Jensen, P., Rouquier, J.-B., Ovtracht, N. \& Robardet, C., Characterizing the speed and paths of shared bicycle use in Lyon. Transportation Research Part D: Transport and Environment, 15, pp. 522-524, 2010. DOI: 10.1016/j.trd.2010.07.002.

[13] Jäppinen, S., Toivonen, T. \& Salonen, M., Modelling the potential effect of shared bicycles on public transport travel times in Greater Helsinki: An open data approach. Applied Geography, 43, pp. 13-24, 2013. DOI: 10.1016/j.apgeog.2013.05.010.

[14] Zhao, J., Wang, J. \& Deng, W., Exploring bikesharing travel time and trip chain by gender and day of the week. Transportation Research Part C: Emerging Technologies, 58( Part B), pp. 251-264, 2015. DOI: 10.1016/j.trc.2015.01.030.

[15] Fuller, D., Sahlqvist, S., Cummins, S. \& Ogilvie, D., The impact of public transportation strikes on use of a bicycle share program in London: Interrupted time series design. Preventive Medicine, 54, pp. 74-76, 2012. DOI: 10.1016/j.ypmed.2011.09.021.

[16] Lathia, N., Ahmed, S. \& Capra, L., Measuring the impact of opening the London shared bicycle scheme to casual users. Transportation Research Part C: Emerging Technologies, 22, pp. 88-102, 2012. DOI: 10.1016/j.trc.2011.12.004. 
[17] Zhao, J., Deng, W. \& Song, Y., Ridership and effectiveness of bikesharing: The effects of urban features and system characteristics on daily use and turnover rate of public bikes in China. Transport Policy, 35, pp. 253-264, 2014. DOI: 10.1016/j.tranpol.2014.06.008.

[18] Gauthier, A., Hughes, C., Kost, C., Li, S., Linke, C., Lotshaw, S., Mason, J., Pardo, C., Rasore, C., Schroeder, B. \& Treviño, X., ITDP Bike-Share Planning Guide, ITDP: New York, p 152, 2013.

[19] Zhang, H., Shaheen, S.A. \& Chen, X.P., Bicycle evolution in China: From the 1900s to the present. International Journal of Sustainable Transportation, 8, pp. 317-335, 2014. DOI: 10.1080/15568318.2012.699999.

[20] Norusis, M.J., Cluster analysis (Chapter 17). IBM SPSS Statistics 19 Statistical Procedures Companion, Prentice Hall: New Jersey, pp. 375-404, 2011. 